final version prior to publication - Ansbro, M (2008) Using attachment theory with offenders Probation Journal Vol 55 No. 3 231-244.

\title{
Using Attachment Theory with Offenders
}

\begin{abstract}
Attachment theory has routinely been considered essential for those working with children. However, contemporary literature and research on attachment offers some compelling insights for work with offenders, particularly in the way that empathy is developed and mood is regulated.
\end{abstract}

\section{Keywords}

Attachment, security, attunement, empathy, self-regulation.

\section{Introduction}

Summaries always run the risk of being crude oversimplifications, but if one had to summarise the recent history of the theories and methods used in the Probation Service it would go something like this. Much of the twentieth century was spent first being driven by an evangelising desire to save offenders, and then by applying an often psychodynamically informed treatment model. By the 1970's a political awareness of the social roots of crime cast such deterministic views into disfavour. Worse was to follow, when all methods of intervention available to the criminal justice system were declared ineffective. At least that was how it was perceived when an American academic called Robert Martinson published an article in 1974 that is now usually alluded to as the "nothing works" article (it's full title was "What works? Questions and answers about prison reform"). In fact the liberally inclined Martinson hoped his findings would lead to a reduction in the use of imprisonment (why bother if nothing worked?) and he was appalled when his material was used to justify entirely contrary policies. 
During the 1980's, cognitive behavioural methods of work arrived in this country from Canada, and breathed new life into the rehabilitative ideal. Key figures in the Probation Service such as Andrew Underdown promulgated their effectiveness, and oversaw their national implementation (Underdown 1998) Programmes designed to teach offenders new thinking skills were adopted enthusiastically, and they remain a key plank of evidence based practice delivered by the National Offender Management Service (NOMS). Chapman and Hough (1998) and set out the Home Office's expectation that all practice in the Probation Service would conform to the principles of "what works"; essentially cognitive behavioural programmes (delivered according to risk, need and responsivity), delivered with large helpings of motivational interviewing and pro-social modelling. Such methods have since produced mixed results, sometimes showing reductions in reconvictions and sometimes not (Harper \& Chitty 2005). There is no doubt that programme work suits some offenders very well, but in the Probation Service a climate has developed in which other methods are frowned on. It has come to feel as if cognitive behavioural programme work is the only trick that the NOMS pony can perform. Rod Morgan (Chief Inspector of Probation at the time) wrote in the Inspectorate's 2002 Annual Report on the Probation Service that the "what works" agenda was being accompanied by "a degree of programme fetishism".

Despite this trend, there have been exciting ideas expounded in recent years that offer contrasting ways of conceptualising offending and devising interventions. Of particular interest is the "criminal careers" literature that reveals clear patterns of desistance and persistence (Farrington 1997, Maruna et al 2004, Farrell, 2005). This research has identified the constellation of factors that predispose individuals to embarking on a criminal career, and likewise the factors that are associated with growing out of crime. Importantly, the work on desistance has found a natural partner with that on the "narrative", which proposes that the opportunity to mentalise and verbalise a narrative of one's life, re-writing the script from a hopeless one to an optimistic one, can be instrumental in the choice to desist. It is proposed that one place where that re-scripting can take place is within a relationship with a Probation Officer/Offender Manager (Burnett and McNeill 2005) 
This article proposes that attachment theory similarly deserves a place in the selection of alternative ideas vying for some space alongside cognitive behaviourism. Moreover attachment has congruence with the ideas around desistance and narratives because it also proposes that the quality of the relationship between offender and worker is pivotal to effective intervention.

Any cognitive behavioural therapist would agree that the quality of the relationship between client/patient/offender effects outcome. However, the way that this method of work has been translated into the language of offender management has sometimes made the notion of a relationship (and the empathy and support that goes with it) an embarrassment, something politically unpalatable. In comparison, challenging attitudes and breaking down denial struck just the right note.

Attachment theory examines the early emotional connection between infant and carers, and how the quality of attachment effects our later development. It is generally proposed that parents and carers who offer a "secure base" (a style of caring that is responsive and in tune with the child's state of mind) tend to turn out psychologically healthy children, who as adults can form good relationships, empathise with others and can modulate their own extreme emotions without losing control. Not even the most fervent advocate would pretend that the quality of attachments is uniquely formative. However, when considered as part of a constellation of social and psychological factors, it contributes to an understanding of patterns of cognitions and behaviours that practitioners frequently struggle with in their work.

\section{Attachment theory misunderstood}

The connection between early neglect or abuse and later problems is written into the fabric of our lives. It is evident in these two quotations, the first from the lyrics of West Side Story sung by gang members of the "Jets", and the second from a Philip Larkin poem, presenting his typically toxic take on life; 
"Gee, Officer Krupke, we're very upset;

We never had the love that ev'ry child oughta get...

...we're depraved on account we're deprived!"

(Sondheim 1957)

"They fuck you up, your mum and dad.

They may not mean to, but they do.

They fill you with the faults they had

And add some extra, just for you".

(Larkin 1974)

However, the very ubiquitousness of the connection between early care and later development can result in it being misunderstood as altogether too commonsensical, deterministic and excusing of personal responsibility. In reality attachment theory does much more than set down a simple connection; it goes on to offer a rich analysis of the mediating psychological processes, with important messages for practice.

Another corruption of attachment theory occurs when it is perceived as inherently misogynistic, demanding near unbroken attention from the mother in the critical early years, and burdening her with total responsibility for the child's development. Early Bowlby is employed, (such as his much quoted 1951 statement "mother love in infancy is as important for mental health as are vitamins and proteins for physical health" ) to rail against contemporary family trends, from working mothers to single parenthood and high divorce rates. This is certainly a misuse of the theory, as attachment theorists place no special mystique upon the maternal bond, instead focusing on the primary caregiver or caregivers, and have come to examine the quality of interactions rather that the amount of time spent with a primary carer.

\section{Attachment, the secure base and offending}


John Bowlby is credited with the genesis of attachment theory, and the subject is now widely taught across the disciplines of psychology and social care. Bowlby trained as a psychoanalyst, but was soon drawn to a more eclectic approach to development, which could acknowledge the effect of environment as well as the inner world. He was struck by the responses - initially despair, then withdrawal and detachment - of children when they were admitted to hospital. His observations were made in the 1950's, when parents were allowed infrequent visits, as they were seen as disruptions to the hospital regime. Whilst pre-1950s society was not entirely oblivious to the emotional needs of children, the need for this human attachment was certainly underestimated, demonstrated amply by film of 1950's maternity wards, with infants bundled up and trolleyed off to a separate room, to be reunited with their mothers at regular 4 hour intervals for feeding.

From work like this two important conclusions were arrived at. Firstly infants need more than to be kept warm and well fed. They need an ingredient that came to be termed security - a quality of care that was sufficiently responsive to the child's needs to alleviate anxiety and engender a feeling of being understood. Secondly, it was proposed that when this was absent, development was likely to suffer. Such work, and all that evolved from it, has been crucial in informing obstetrics and child welfare services, and early work on attachment also drew a connection between quality of early attachment and later delinquency. Bowlby himself (1944) wrote a research paper based on a cohort of 47 young offenders, proposing that the absence of a secure attachment figure can result in "affectionless psychopathy" - a condition characterised by a lack of concern for others, and an inability to form relationships. The term has, over the years, come to sound dated, and yet has a prescience when one considers contemporary studies of personality disorder and risk of harm.

More contemporary research confirms the connection between early adverse experiences, and later offending and mental health problems. The Cambridge Delinquency Study (Farrington 1997 and various dates) has been perhaps the 
most thorough longitudinal study undertaken in this country. For nearly forty years it has followed a cohort of 411 males born in south London, and has identified a number of factors that set the group that came to offend apart from the group that did not. The offending group were more likely to have behaved anti-socially as children, and to have displayed hyperactivity, excessive impulsivity and attention deficit. The offenders' families were more likely to have had convicted criminals as members, and to live in poverty, as measured by income, family size and quality of housing. Most importantly for the purposes of this paper, the offending group were more likely to have received parenting characterised by poor supervision, and harsh, authoritarian discipline, and their parents were more likely to be in conflict with each other. Without doubt these factors interact with each other, but the quality of parental care stands out as an important mediating factor in the child's developmental pathway.

On a smaller scale, and focusing on a specific, "heavy end" group of offenders, Gwyneth Boswell, (1998) looked at the backgrounds of 200 of the most serious young offenders in the UK Criminal Justice System. They were being detained indefinitely because they had committed offences such as murder, arson or rape. She confirmed from their files that nearly all of them had experienced severe loss, neglect or abuse. To turn to the connection between mental disorder and early attachment, there is, equally, a range of supportive evidence. Luntz and Widom (1994) found that in a large sample of American children who had been subject to abuse or neglect in their early years there were significantly more who were diagnosed with Anti-Social Personality Disorder (ASPD) in adulthood than in a control group who had not been abused. However this last piece of research reminds us of one of the most important caveats in this area, namely that whilst the connection between absent or disturbed early attachment and later development is true for some, there remains the majority who develop well despite their experiences; $13.5 \%$ of the experimental group developed the disorder compared to $7.1 \%$ of the control group, leaving the majority without the condition. The possibility of different developmental pathways by gender was 
also raised, as the adverse early experiences did not act as a significant predictor for ASPD for the girls in the way that it did for the boys.

Human development is too complex to isolate particular factors as causative, but in all these pieces of research the quality of early parenting emerges as one factor that is important in determining later development. Psychologists like Daniel Stern (1977) have studied the psychological processes at a micro level that transmit these effects. He analysed interactions between carers and infants, their gurgling precursors to verbal conversations, noting the patterns of facial expressions and vocalisations. He proposed that in the majority of cases there is an intuitive attunement in these interactions, a finely tuned modulation, from which the infant learns that the carer is available, and can understand and respond. When the baby is alarmed or in distress the carer soothes and the baby finds his or her equilibrium without recourse to panic or major upset. If a baby is left to deal with too much panic and fear on its own too early - perhaps because the carer is disengaged through mental illness or substance misuse - the infant does not start to learn this route through anxiety into relief.

The idea of early attachment providing an essential ingredient for emotional and cognitive growth can be taken further. Fonagy (2004) proposes that the carer's responsivity gives the infant the first inkling that the way he or she feels is understood in another persons mind. The tendency to somewhat exaggerate facial expressions when communicating with babies (excited euphoria at babies first wave, abject misery when baby bumps head) is more than adult gooiness - it is the mechanism by which baby starts to compile his or her inner vocabulary of emotions, and goes on to refine a meta-cognitive ability (the capacity to access ones own thoughts and feelings, to "think about thinking") over the years. In this way the infant learns to recognise their own emotions and read other people's.

Security of attachment is an indicator of (but not a guarantee of) good social and emotional development, as measured by independence, sociability, and absence of behavioural problems (Thompson 1999). Securely attached 
children go about life with a blueprint about relationships that is essentially trusting; they have had enough caring that is in tune with them to be able to get on with life. Rather than having to worry about whether the carer is going to be available for the scary moments, and on their wavelength, they are more or less confident that they will be, and will probably be understood. The child is free to to get on with important developmental tasks like playing, making friends and learning. For the minority of children who display insecure attachments, less optimal strategies are developed, with implications for their development.

\section{Types of attachment}

Types of attachment were first defined by Mary Ainsworth (1985), who devised the "strange situation experiment". This was, and continues to be used as a procedure that reveals the type of attachment an infant has. It is performed at a developmental point when the child has particular attachments, but is not so sophisticated that emotions and reactions are rationalised and disguised. The toddler and their carer enter a room where there is a researcher and a few toys. After a while the carer leaves. Whether or not the child gets upset when they are left with the researcher is not particularly relevant - it is how they respond to the carer's return that is revealing.

The majority of infants have some contact with the carer on their return; they may need comforting but that contact serves the purpose of bringing them down from any upset and re-establishing equilibrium. Within a short space of time they are back playing. This response is characteristic of secure attachment; even though they have been worried by being left, they are able to get over the anxiety by the attention of their attachment object. A minority of infants show a different type of response in the Strange Situation Experiment reactions that indicate insecure attachments. Ainsworth has discerned three main types of insecure attachment. One group showed what has come to be known as an avoidant style of attachment, and they seemed to be detached from their carer when they returned. Superficially they continued with what they were doing, although they kept one eye on the carer. The other 
insecurely attached group showed a mixture of responses - they might welcome the carer back, but then shy away or rebuff. Their responses could be quite contradictory, and this came to be called an ambivalent style of attachment. These types of attachment have been found to be fairly universal, with the majority falling into the securely attached group, and this group showing optimal development.

The question that next has to be posed is what steers a child towards secure or insecure attachments, and the crucial influence seems to be the style of care received. Although temperament has some part to play in the infant's style of attachment the most important factor is the attunement and availability of care received from the primary carers (Belsky \& Rovine 1987). Avoidantly attached children are likely to be parented in a cold, punitive or violent manner and ambivalently attached children are likely to have received inconsistent parenting, a mixture of attention and disregard, warmth and coldness, but delivered unpredictably and not in response to the child's state. A parent who is, for instance, a heavy drinker may be maudlin and affectionate at times, but at other times angry and violent.

It would be artificial to see these attachment types as fixed and distinct, like a blood type. As ever, reality is somewhat fuzzier than the model describes. Ainsworth (1985) put forward the notion of a continuum, with secure attachment at the mid-way point, and the two main types of insecure attachment at extreme ends on either side. However, there does seem to be something enduring about the attachment type which individuals tend towards. These early patterns have longevity - Bowlby used the term "internal working model" to describe the way that early attachments form prototypes for later relationships. The "Adult Attachment Inventory" is a structured assessment tool devised by Mary Main which evaluates adults' attachment styles, and it confirms the tendency for adults to demonstrate similar styles of attachment as they did when small (Van Ijzendoorn 1994). Avoidant children tend to grow into adults with what is termed a "dismissing" style of attachment. A parental style of care which is consistently cold, critical, punitive or violent will signal to the child not to expect what is needed emotionally. This does not mean that 
the child will not love the parent - in fact the reverse may be true, as suggested in Winnicott's famous phrase (cited in Holmes 1994) that it is "better to cling to a bad object than to have none at all". However, to protect against disappointment or worse, the avoidantly insecure child cannot afford to expect much and detachment provides protection. The dismissing adults, who tend to develop from such early attachments, often repeat this style in their own adult relationships - avoiding closeness with others, and displaying little interest or awareness of their own or others state of mind. Ambivalent children, tend to develop "preoccupied" or "enmeshed" styles of attachment as adults, anxiously alternating between a wish for intimacy and a need for distance. Insecure types of attachment are not optimal for development and a wealth of research has amassed confirming the disadvantages of insecure attachments (Thompson 1999).

What these two forms of insecure attachment have in common is that the attachment object cannot be trusted. Different strands in psychology often arrive at with similar ideas under different headings, and this idea echoes those of Erik Erikson. Erikson mapped out the stages of life, and proposed that each one was characterised by a different challenge. The first one, the most fundamental and the one with the most serious consequences if things do not go well, is the battle between trust and mistrust. In the first year or two, the child is learning whether the world around it is reliable, predictable, and more or less benevolent - in other words the conditions to nurture security. Attachment theorists propose further that if you have not experienced someone who has been in tune with your state of mind, it is difficult, in turn, to be in touch with others states of mind. Again we can witness ideas from different fields in psychology converging. This idea adds to work from cognitive psychology, where perspective taking, de-centring, and development of a "theory of mind" are proposed as capacities that evolve as part of the maturational process.

\section{Neuropsychology and attachment}


Recent years have seen exciting developments linking attachment experiences with the physical development of certain brain structures. Allan Schore, a psychobiologist, has found that those with secure attachments have a more developed pattern of neurotransmitters in the limbic system - which is precisely the area of the brain known to play an important part in the regulation of the emotions. Schore (1997) has studied the neurobiological states that accompany varying types of infant care, and argues that good enough attunement promotes the wiring of healthy brain circuitry. If we recall the earlier work of Stern (1977), his examinations of mother and infant interactions revealed how the carer and infant lock their gazes together, their expressions modelling and mirroring one another. By tuning in to every subtle shift in the infants states, the caregiver accentuates positive states of excitement, joy and pleasure, and minimizes distress. The infant feels that its inner state is understood by another and in this way the mother serves as an affect regulator, and a template for later independent regulation. These early empathic, attuned experiences seem to promote the development of synapses in the orbitofrontal cortex in the limbic system. Schore contends conversely that abuse, neglect and chronic states of misattunement lead to an overpruning of synapses in the orbitofrontal cortex, leaving individuals with an impaired ability to modulate and regulate emotion in response to stress.

There is another aspect to the physiological correlates of attachment, and that is in the release of cortisol. This is the hormone that is released when under stress, and which causes the "fight or flight" response in the body. When securely attached individuals are exposed to alarm, cortisol is released and then tapers off. Secure attachments seem to equip the individual to recover from anxiety. Insecurely attached individuals in contrast seem to have chronically elevated levels of cortisol, making them constantly primed for an emergency (Spangler and Schieche 1998). The securely attached use their secure base to reduce anxiety, and go on to learn to do that for themselves. Without that experience, the avoidant group's strategy is to self-manage by detachment, while the ambivalent group devotes much attention and emotional energy to coping with the unpredictability. Ultimately the result is the same - the attachment object cannot be relied on. The implications are that 
early experiences underpin organic and chemical differences in brain functioning, and that inadequate care may leave individuals poorly equipped to manage levels of arousal.

\section{Applications with offenders}

Type of attachment is not posited as a failsafe early predictor of later development. Many adults who have experienced disrupted or deficient attachments when young will, from whatever source, find sufficient resilience to grow into well-balanced adults. David Howe (2005) has suggested that the intelligence to reflect on adverse experiences and the opportunity to mentally metabolise them with another makes for resilience. The Dunedin study (a longtitudinal study in New Zealand) suggests that there is a genetic ingredient interacting with the environment to offer such protection (Caspi et al 2002). However, if we look at a population of offenders - particularly those with deepseated problems, we find a preponderance of insecure attachments.

Ward and Hudson (1996) looked at a group of sexual offenders, and assessed their type of attachment style. What was clear was that child molesters were more likely to have preoccupied styles of attachment (perhaps reflecting an inability to cope with adults in relationships, where they expect both unbearable intrusions and awful abandonment) and the rapists (in common with generally violent people) tended to have dismissing styles (perhaps reflecting their lack of empathy with others, inability to control aggression, and avoidance of real intimacy).

Gwen Adshead (2002) has confirmed the over-representation of dismissing styles in a population of violent offenders in Broadmoor. She comments "It is likely that a dismissing state of mind is linked with a developmental failure of empathy, which implies some degree of self-reflective function: it is hard to imagine the feelings of others if there is diminished capacity to think about one's own feelings" (P 35). 
For practitioners all this becomes salient when we are working with offenders who fail to understand and control their extreme states of mind (for example as in anger management work) and who are unable to access others states of mind (for example when working to cultivate empathy towards victims). The essential psychological capacity that is required for both of these is the ability to "think about thinking" - to know when you are feeling angry or low, and even better to have some insight into what might make you feel different. This capacity is sometimes referred to as the "self-reflective function" (Fonagy 2004) and also "meta-cognition" (Main 1991). Securely attached individuals think about their feelings and relationships, and although they are not necessarily idyllic they can contemplate them and make sense of them. We are likely to be working with individuals who are not used to doing this. A dismissing style of attachment would typically result in an adult who could not put into words what their relationships were like. They might recall early family life as "fine", (even when all the indications are to the contrary) but be unable to put much detail on that response. Having an attachment object who can understand your state of mind allows you to grow into an adult who can do the same thing to others. Having an attachment object who does not want to, or cannot take in your state of mind forces the adoption of another strategy, one which will not include accessing your own state of mind or others. For practice this is useful. Many of our clients are not being wilfully obtuse when they seem oblivious to others' situations, whether it is their own partner or a victim of their robbery. Development of the self-reflective capacity (clear echoes here of narrative work) with the assistance of a Probation worker offering a taste of secure base add to and complement a cognitive behavioural understanding of empathy.

The second important application with offenders, and somewhat connected to the last point in that it is about accessing others and our own psychic state, is the ability to regulate our own emotion. Secure attachments serve to reduce anxiety when life gets scary. In the strange situation experiment the securely attached infants became upset just as much as the others when they were left - but crucially they were able to use their secure base to be soothed and were soon off playing independently again. Ideally, that process, the "don't worry, 
it's alright" feeling becomes internalised and the capacity to self-manage through extremes of emotion develops. Without that capacity, however, other less optimal other strategies are resorted to. A dismissing style of attachment, with its typical detachment from emotion and thought, is likely to fast forward the individual straight into a behavioural, sometimes violent response, or short cuts will be found to regain equilibrium - alcohol, drugs, violence, sexually abusive acts. Attachment theory should reassure practitioners that time spent establishing a well pitched dialogue, and starting to put words to offender's thoughts and state of mind is time well spent. Although it may not lent itself to concrete target setting or completion of paper based exercises, it will be nurturing an ability to recognise and verbalise emotional states - something that other psychological perspectives would call emotional intelligence or emotional literacy.

Sexual offenders are, arguably, more studied and researched than any other group of offenders, and so it is no surprise that the literature in this field already employs ideas from attachment. Marshall and Barbaree (1990) have formulated an integrated theory of sexual offending which draws on the range of evidence and ideas. They make a connection between early attachments and later problems in managing negative states of mind, establishing intimacy, and feeling empathy - difficulties experienced by many sexual offenders. Ward (2002) comments on Marshall and Barbaree's integrated theory thus; "insecure attachment is viewed as particularly important as it results in a failure to explore the world and to develop trust and a sense of personal security and power ...... insecure attachment results in enduring problems with mood management, low self esteem, impaired problem solving and reduced self efficacy." (P212).

The Kids Company in Peckham is run by Camila Batmanghelidjh and is a centre for troubled children and adolescents. Moreover it provides an illustration of the application of attachment theory with young offenders. There is nothing exclusively psychotherapeutic about her centre (it offers practical services ranging from food to home redecoration as well as psychotherapy), but she traces the emotional journey from neglected or abused child to 
brutalised adolescent in terms of their attachments. Batmanghelidjh describes these children and adolescents as "emotionally exhausted" and "suicidally brave". She sees value in the therapist/worker showing exaggerated emotional responses to the youngsters who not venture into their own emotions. Thus "you've been stabbed, you're not feeling much pain but I am upset for you" offers a grown up version of Stern's carers providing a mental model of the infants state of mind for the infant to internalise This can, when the moment is right, give a moment of rekindling of their emotional repertoire.

Batmanghelidjh posits the staff group of Kids Company as collectively representing a secure base - in fact she believes that the more disturbed the young person, the more important it is for them to avoid having attachments ruptured. The NOMS management model (2005), with its aspiration for "end to end management" is, in its own way, acknowledging this need. It states that offenders should be provided with a continuous supervisory relationship where possible, but even when there are inevitable changes (when leaving custody, or when staff leave), then they should receive consistency of service. The application of attachment theory would suggest to us that, for instance, when transferred between staff an offender should be kept informed about the process, should be in no doubt that the new worker knows what has gone before, and should know exactly what is expected of them. Where possible there should be an opportunity for all parties to meet, to give offender the experience of the role being passed on. Gaps in contact and unclear arrangements simply replicate the behaviour of unreliable attachment figures from the past.

To extract the message from all of this for practice with offenders is at once simple and complex. The literature on offenders (e.g. Andrews \& Bonta 2002) proposes particular "cognitive deficits" (particularly lack of empathy and excess impulsivity) amongst offending populations. The aim of cognitive behavioural interventions is, put simply, for offenders to learn to think differently. Attachment theory elaborates on the cognitive behavioural framework; it helps us speculate about what experiences might have led to such deficits, to appreciate them as deeply rooted rather than mere gaps in 
learning, and to understand how workers in the Probation Service can provide a taste of a secure base.

To have some understanding how empathy and self regulation grows out of early attachment experiences gives us the "back-story" to the cognitive deficits that are recited in the cognitive behavioural literature. We can understand that, whilst early experiences in no way excuses later offending, a tendency towards impulsivity and an inability to see others perspectives have deepseated origins. Moreover, in our contact with offenders we can try to replicate in a small way a good attachment object, one that tries to sense the state of mind of the offender and respond. What an attachment framework has in common with narrative work is a belief that the relationship in itself is a tool that can effect change, that the quality of the rapport that is in itself an instrument of intervention. Here we arrive at something which is qualitative and therefore difficult to measure. Whereas it is possible to measure whether a particular exercise in a cognitive behavioural programme has been delivered according to the programme instructions, it is more a matter of judgement to say whether the worker has been in tune with the state of mind of the offender, has made finely tuned interventions, and has been a deft wordsmith to help the offender put words to thoughts and feelings. This tension between quantitative and qualitative work has parallels with that between evidence based practice and reflective practice. Hopefully the state of offender management is now sufficiently mature to accommodate both perspectives. As far as we can we should measure the effects of our work, but we should remember that sometimes things that matter are difficult to measure.

\section{Conclusion}

So, we have a school of ideas, bound by the central notion of attachment which is not tied to one particular end of the cognitive/psychodynamic spectrum. Rich (2006) explains attachment's congruence with cognitive behavioural approaches thus; "cognitive distortions are drawn from the 
cognitive map, or internal working model we form of the world through our early and accumulative attachment experiences, which contains scripts and automatic thoughts that form the basis for our ideas, beliefs, attitudes and eventually behaviours" ( $p$ 214). At the other end of the theoretical spectrum, attachment theory is congruent with the object relations school of psychodynamic thought, viewing early attachments as critical in the development of the "agentive mind", and the metacognitive capacity to reflect. An attachment framework does not give us a set of exercises or a workbook in the way that cognitive behaviourism can, but it offers us a way of understanding our offenders, re-activating their sense of being understood, and nurturing their understanding of themselves and others. 


\section{References}

Adshead, G. (2002) "Three degrees of security; attachment and forensic institutions." Criminal Behaviour and Mental Health, 12, S31-45

Ainsworth, M. (1985) Patterns of attachment. Clinical Psychologist, 38, 27-29

Andrews, D. A., \& Bonta, J. (2002). The Psychology of Criminal Conduct (3rd ed.). Cincinnati, $\mathrm{OH}$ Anderson.

Batmanghelidjh, C. (2007) Tavistock Clinic Guest Lecture Series, $7^{\text {th }}$ April 2007

Belsky, J. \& Rovine, M. (1987), Temperament and attachment security in the strange situation: An empirical rapprochement. Child Development 58, 787 797

Boswell, G. (1998) Research-minded practice with young offenders who commit grave crimes. Probation Journal, 45, 202-297

Bowlby, J. (1944) Forty-four juvenile thieves: Their characters and home lives International Journal of Psycho-Analysis ,XXV, 19-52

Bowlby, J. (1951) Maternal Care and Mental Health World Health Organisation Monograph 
Burnett, R. and McNeill, F. (2005) The place of the officer-offender relationship in assisting offenders to desist from crime. Probation Journal, vol. 52: pp. 221 242.

Caspi, A., McClay, J, Moffitt, T., Mill, J., Martin, J., Craig, I, Taylor, A., \& Poulton, R. (2002). Evidence that the cycle of violence in maltreated children depends on genotype. Science 297, 851-854.

Erikson, E. (1968) Identity: Youth and Crisis Norton

Farrell, S. (2005) Understanding Desistance from Crime: Theoretical Directions in Resettlement and Rehabilitation. Milton Keynes: Open University Press

Farrington, D.P. (1997) "Human development and criminal careers", in M.Maguire, R Morgan and R.Reiner, eds. The Oxford Handbook of Criminology, $2^{\text {nd }}$ edition, Oxford: Clarendon Press

Fonagy, P. (2004) The developmental roots of violence in the failure of mentalization, in F. Pfafflin and G. Adshead A Matter of Security: The Application of Attachment Theory to Forensic Psychiatry and Psychotherapy.

Harper, G. and Chitty, C. (2005) The Impact of Corrections on Re-offending: a Review of 'What Works'. Home Office Research Study 291

Holmes, J. (1994) The Clinical implications of attachment theory, British Journal of Psychotherapy 11 (1), 62-76.

Howe, D. (2005) Child Abuse and Neglect: Attachment, Development \& Intervention. London: Palgrave/Macmillan

Larkin, P. (1974) "This be the verse", in High Windows, Faber and Faber 
Luntz, B. \& Widom, C. (1994) Anti-Social personality disorder in abused and neglected children grown up. American Journal of Psychiatry 151 (5) 670-674

Main, M. (1991) Metacognitive knowledge, metacognitive monitoring, and singular (coherent) vs. multiple (incoherent) model of attachment: findings and directions for future research in Parkes, C.M., Stevenson-Hinde, J. and Marris, P. (eds.) Attachment Across the Life Cycle. London: Routledge

Marshall, W. \& Barbaree, H. (1990) An integrated theory of the etiology of sexual offending. In W. Marshall, D.R Laws and H. Barbaree (Eds.), Handbook of Sexual Assault: Issues, Theories and Treatment of the Offender (pp 257275). New York: Plenum

Martinson, R. (1974) What Works? Questions and answers about prison reform The Public Interest, 10: 22-54

Maruna,S. Porter, L. and Carvalho I, 2004. The Liverpool desistance study and probation practice: Opening the dialogue. Probation Journal; vol. 51: pp. $221-232$.

Morgan, C (2002) Annual Report of the Inspectorate for the Probation Service for England and Wales today, HMIP

Rich, P. (2006) From theory to practice: the application of attachment theory to assessment and treatment in forensic mental health services. Criminal Behaviour and Mental Health, 16, 211-216

Schore, A.N. (2007) Early organisation of the nonlinear right brain and development of a predisposition to psychiatric disorders. Development and Psychopathology, 9, 595-631

Sondheim S, (1957) Lyrics to West Side Story, Columbia Broadway Masterworks, New York 
Spangler, G. and Schieche, M. (1998) Emotional and adrenocortical responses of infants to the strange situation: The differential function of emotional expression. International Journal of Behavioral Development, 22, (4) 681-706

Stern, D. (1977) The First Relationship: Mother and Infant. Cambridge M.A. Harvard University Press

Thompson, R. (1999) Early attachment and later development. In J. Cassidy \& P. R. Shaver (Eds.), The Handbook of Attachment: Theory, Research, and Clinical Applications (pp. 265-286). New York: Guilford.

Underdown, A. (1998) Strategies for Effective Offender Supervision: Report of the HMIP What Works Project. London: Home Office

Van ljzendoorn, M.V. (1994) Adult attachment representations, parental responsiveness, and infant attachment: $A$ meta-analysis on the predictive validity of the Adult Attachment Interview. Psychological Bulletin 117 (3) 387403

Ward, T. (2002) Marshall and Barbaree's integrated theory of child sexual abuse: a critique. Psychology Crime and Law 8: 209-228

WORD COUNT; 5,874 
